\title{
Educação e saúde: espaços de encontro
}

Roberta Mendes Von Randow, Jadilson Wagner Silva do Carmo, Tatiana Vasques Camelo dos Santos, Maíra de Paula Barbosa, Wesley Alcântara, Emanuel Victor Alves Costa

\section{Resumo}

A educação em saúde constitui-se em uma ferramenta para viabilização de ações direcionadas à promoção e prevenção da saúde de indivíduos, famílias e comunidades. A educação em saúde possui característica transformadora se considerada a corresponsabilização do individuo, família e/ou comunidade e a interação entre o individuo e profissional propiciando troca de saberes. As diretrizes Nacionais dos cursos da área de saúde preconizam a necessidade de formação de profissionais capazes de desenvolver novas tecnologias para educação em saúde, valorizar e implementar ações que visem a melhoria da qualidade de vida; constituindo assim, um desafio para os profissionais da área. Desta forma, o projeto em questão possui extrema relevância, onde a aproximação dos acadêmicos com ações preconizadas pela política de saúde atual. Desenvolver ações de promoção e prevenção à saúde por meio de estratégias de educação em saúde contribuindo na qualidade de vida dos indivíduos. Trata-se de um projeto de extensão desenvolvido desde agosto de 2015, por professores e acadêmicos dos cursos de medicina e enfermagem. São instituições parceiras: Secretaria Municipal de Saúde de Manhuaçu; Divisão de Assistência, Recuperação, Educação e Integração (DAREI); Asilo São Vicente de Paula; Centro de Atenção à Família do Bairro São Francisco de Assis. As ações foram desenvolvidas a partir das seguintes etapas: 1) Diagnóstico e planejamento de estratégia juntamente com instituição parceira e/ou comunidade. 2) Execução da atividade de acordo com planejamento realizado. 3) Avaliação da proposta desenvolvida. Durante 01 (um) ano de realização do projeto foram desenvolvidas ações de educação em saúde direcionadas para idosos de instituição de longa permanência, crianças residentes em instituição assistencial, e adultos pertencentes a uma comunidade. Foram temas das estratégias desenvolvidas: higiene pessoal, autoestima e prevenção de doenças crônicas e suas complicações. As avaliações das intervenções realizadas demonstraram que a aproximação com a realidade do público alvo e a utilização de tecnologias interativas é de fundamental importância para a construção do processo de aprendizagem. A realização de ações com indivíduos de diferentes faixas etárias propiciou o planejamento e execução de ações diferenciadas e direcionadas a cada grupo especifico. Á interação entre os acadêmicos e sujeitos é um ponto forte na criação do vínculo durante o processo de cuidar. As estratégias foram realizadas por meio de: teatros, músicas, apresentações, trabalhos manuais, entre outros. A proximidade das ações acadêmicas com a realidade e o contexto da comunidade é de fundamental importância para ambos, e esta encontra-se prevista nas diretrizes curriculares dos cursos na área da saúde, assim como nas normativas do Sistema Único de Saúde (SUS). A educação em saúde constitui-se em estratégia capaz de contribuir para desencadear este processo, de maneira construtiva e interativa, produzindo reflexão e aprendizado para comunidade de maneira geral, para acadêmicos e professores.

Descritores: Educação em saúde; Saúde coletiva; Promoção saúde. 